\title{
COMPOSIÇÃO QUÍMICA E ATIVIDADE FOTOPROTETORA DE EXTRATOS DE ESPÉCIES DE Physalis (SOLANACEAE)
}

\author{
$\underline{\text { Lucas Souza Silva }^{1} \text {; Alexandre de Freitas Espeleta }}{ }^{2}$; Gabriela Carinhanha Silva ${ }^{3}$ \\ e Iza Miranda Melo Paulo 4 \\ 1. Bolsista PIBIC/FAPESB, Graduando em Farmácia, Universidade Estadual de Feira de Santana, e-mail: \\ lsuefs@gmail.com \\ 2. Orientador, Departamento de Exatas, Universidade Estadual de Feira de Santana, e-mail: espeleta8@ gmail.com \\ 3. Participante do projeto, Doutoranda em Recursos Genéticos Vegetais, Universidade Estadual de Feira de \\ Santana, e-mail: gabicarinhanha@gmail.com \\ 4. Participante do projeto, Doutoranda em Biotecnologia, Universidade Estadual de Feira de Santana, e-mail: \\ izamiranda@live.com
}

PALAVRAS-CHAVE: Physalis peruviana; Physalis ixocarpa; fenólicos

\section{INTRODUÇÃO}

A família Solanaceae inclui uma ampla variedade de plantas que são econômica e farmacologicamente importantes (TOMASSINI et al., 2000). Dentre as plantas desta família, o gênero Physalis L. que inclui 75-90 espécies, predominantemente americanas com distribuição nos Estados Unidos, México, América Central, América do Sul e Antilhas, tem se destacado na família devido ao elevado potencial alimentício, ornamental e medicinal (RUFATO et al., 2008). O potencial medicinal desse gênero é atribuído à presença de um grupo de substâncias derivadas do ergostano, denominadas fisalinas, com atividade biológica já comprovada (BARROSO, 2015).

Devido ao elevado potencial e excelente aceitação no mercado, espécies do gênero são cultivadas em vários países. O Brasil apresenta 8 espécies, distribuídas por todo o país, principalmente na Amazônia e Nordeste (STEHMANN et al., 2015). Dentre essas espécies, Physalis ixocarpa Brot., conhecida popularmente como "tomate de cáscara" ou "tomatillo", é amplamente cultivada e comercializada visando à produção de frutos consumidos in natura e utilizados na culinária (WHITSON; MANOS, 2005).

Outra espécie conhecida é a Physalis peruviana L., nativa dos Andes e denominada popularmente no Brasil como "fisalis". Amplamente cultivada na Colômbia e na África do Sul, seu cultivo está expandindo na Região Sul do Brasil (CEDENÕ e MONTENEGRO, 2004). Seus frutos possuem grande valor nutricional e econômico (SEVERO et al., 2010).

Os frutos de $P$. ixocarpa e $P$. peruviana têm sido amplamente estudados, mas poucos relatos na literatura referem-se as demais partes aéreas dessas plantas. Assim, o objetivo deste trabalho foi avaliar a composição química e a atividade fotoprotetora dos extratos das folhas e caule de P. ixocarpa e P. peruviana.

\section{MATERIAL E MÉTODOS}

As folhas e os caules de $P$. peruviana foram secos separadamente à temperatura ambiente, ao abrigo da luz, sendo posteriormente pulverizado em moinhos de facas, bem como as folhas de $P$. ixocarpa. $\mathrm{O}$ material pulverizado foi submetido à maceração em metanol e o solvente foi removido em evaporador rotativo, sob pressão reduzida. O resíduo de solvente foi retirado por evaporação em capela de exaustão para obtenção dos extratos metanólicos brutos das folhas de $P$. ixocarpa e das folhas e caule de P. peruviana.

O teor de fenólicos foi determinado por espectrometria no UV-Vis $(750 \mathrm{~nm})$, pelo método de Folin-Ciocalteau, utilizando ácido gálico (AG) como padrão (PERES, 2009). A determinação de flavonoides foi por reação com $\mathrm{AlCl}_{3}$ em espectrometria no UV-Vis (425 nm), utilizando quercetina (Q) como padrão (BANOV, 2006). 
A atividade fotoprotetora foi avaliada através da análise da determinação do comprimento de onda máximo $\left(\lambda_{\text {máximo}}\right)$ e da absorbância máxima $\left(\mathrm{A}_{\text {máxima. }}\right)$ e posterior cálculo do fator de proteção solar dos extratos brutos, conforme Violante e colaboradores (2009).

\section{RESULTADOS E DISCUSSÃO}

Os teores de fenólicos e flavonoides totais dos extratos das folhas e caule de $P$. ixocarpa e $P$. peruviana estão reunidos na Tabela 01 .

Tabela 01. Teor de fenóis e flavonoides totais do extrato das folhas e caule de $P$. ixocarpa e P. peruviana.

\begin{tabular}{|c|c|c|c|}
\hline \multicolumn{2}{|c|}{ Extratos Brutos } & $\begin{array}{c}\text { Fenólicos } \\
\text { Média }( \pm \mathrm{DP}) \mathrm{mg} \text { EAG/g }\end{array}$ & $\begin{array}{c}\text { Flavonoides } \\
\text { Média }( \pm \mathrm{DP}) \mathrm{mg} \mathrm{EQ} / \mathrm{g}\end{array}$ \\
\hline \multirow{2}{*}{ P. peruviana } & Folhas & $59,97 \pm 6,42$ & $33,06 \pm 4,04$ \\
\hline & Caules & $46,85 \pm 1,63$ & $9,63 \pm 1,20$ \\
\hline P. ixocarpa & Folhas & $64,95 \pm 2,85$ & $33,68 \pm 2,90$ \\
\hline
\end{tabular}

Legenda: EAG (equivalente de ácido gálico); EQ (Equivalente de Quercetina); DP (Desvio Padrão).

O teor de compostos fenólicos produzidos por uma planta é considerado fator importante para sua própria proteção contra a radiação ultravioleta emitida pelo sol. Além disso, os flavonoides também atuam dissipando a energia UV absorvida de uma maneira inofensiva (MARKHAN et al., 1998). Dessa forma, os extratos de plantas que contêm esses compostos são capazes de absorver a luz ultravioleta, sendo possível o uso destes extratos como filtros solares em preparações fotoprotetoras (BOBIN et al., 1994).

Conforme observado no perfil de absorção espectrofotométrica dos extratos secos das folhas e caule de $P$. ixocarpa e $P$. peruviana (Figura 01) mostraram bandas de absorção características, com seus máximos na região UVC, de forma dependente da concentração.

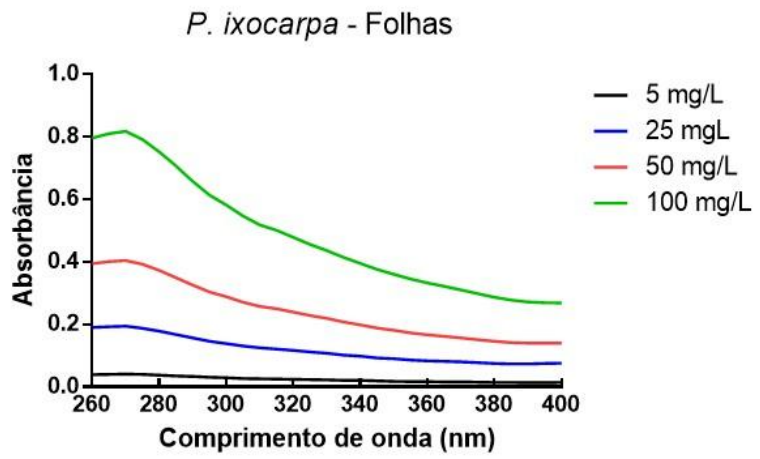

P. peruviana - Folhas

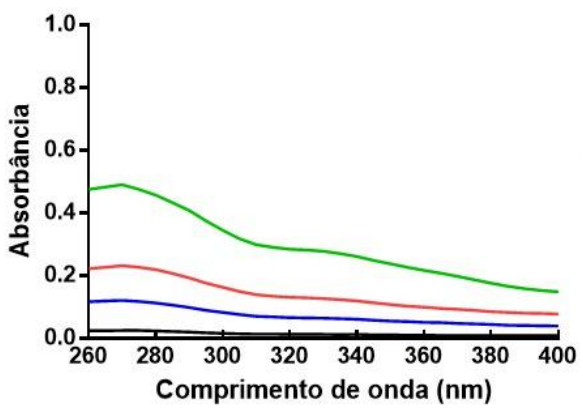

P. peruviana - Caule

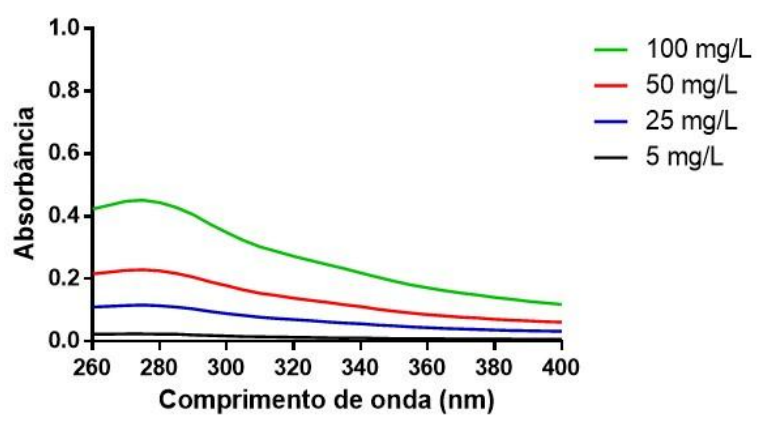

Figura 01. Espectro da varredura UV (260 a $400 \mathrm{~nm}$ ) da diluição dos extratos secos das folhas e caule de $P$. ixocarpa e $P$. peruviana. 
A amostra que mais absorveu foi o extrato das folhas de $P$. ixocarpa com 0,81 de absorção em $270 \mathrm{~nm}$. Os extratos das folhas e caule de $P$. peruviana mostraram valores de absorção semelhantes entre si, com 0,49 de absorção em $270 \mathrm{~nm}$ e 0,49 de absorção em $275 \mathrm{~nm}$.

Para a determinação do Fator de Proteção Solar utiliza-se um método espectrofotométrico in vitro desenvolvido por Mansur et al. (1986), que correlaciona-se bem com os testes in vivo pois relaciona a absorbância da substância em questão com o efeito eritematógeno da radiação e a intensidade da luz em comprimentos de ondas determinados entre 290 a $320 \mathrm{~nm}$, espectro específico da região UVB, considerada a região de maior incidência durante o dia em que as pessoas estão expostas por mais tempo (DUTRA et al., 2004; VIOLANTE et al., 2009).

$\mathrm{Na}$ Figura 02 pode-se observar que os maiores valores de FPS foram apresentados para os extratos a $100 \mathrm{mg} / \mathrm{L}$, sendo 5,5 $\pm 0,29$ para as folhas de $P$. ixocarpa, e 3,23 $\pm 0,25$ e 3,26 $\pm 0,17$ para as folhas e caule de $P$. peruviana respectivamente.
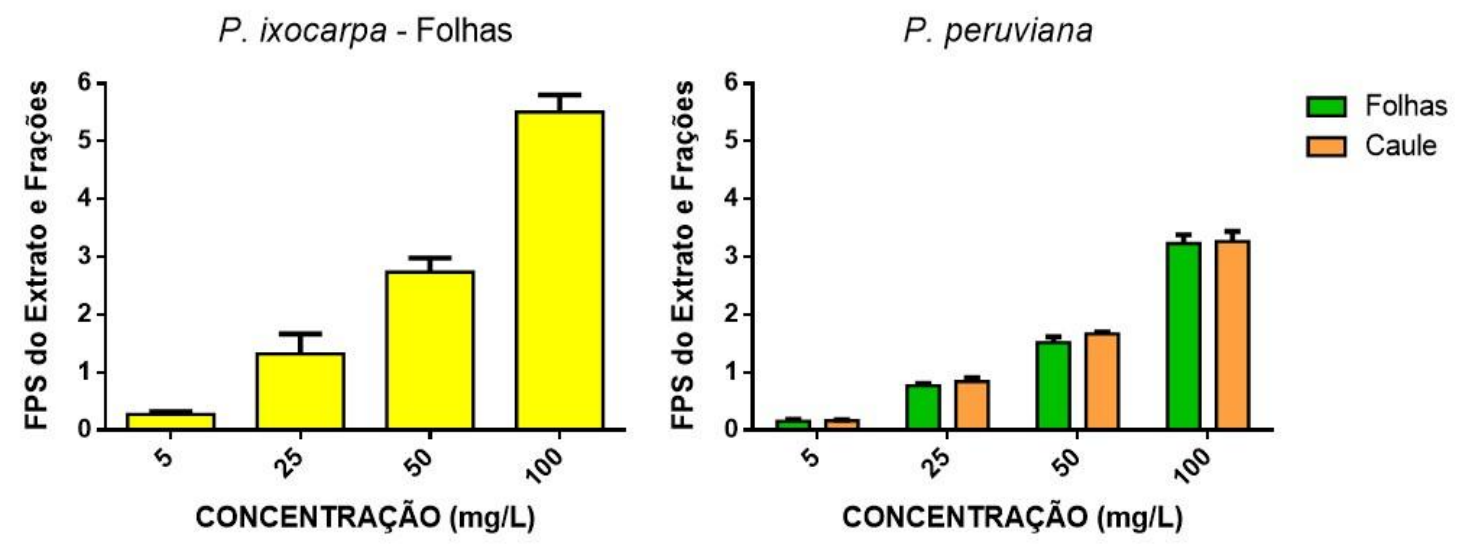

Figura 02. Fator de Proteção Solar (FPS) dos extratos secos de $P$. ixocarpa e $P$. peruviana.

A atividade fotoprotetora, depende da capacidade de absorção de energia radiante atribuída aos grupos cromóforos, que é proporcional à sua concentração, intervalo de absorção e comprimento de onda onde ocorre absorção máxima. Desta forma, os baixos valores de absorção e de FPS apresentados pelas amostras pode ser decorrente da concentração das moléculas com atividade absorvedora da UV, corroborando com a afirmação realizada por Bobin et al. (1994), que destaca a dificuldade da determinação da absorção máxima dos produtos vegetais, por serem uma mistura complexa de moléculas mais ou menos ativas.

\section{CONSIDERAÇÕES FINAIS}

A melhor atividade fotoprotetora foi de 5,5 $\pm 0,29$, observada para o extrato das folhas de $P$. ixocarpa, mas apenas na concentração mais elevada. Este valor está próximo ao limite mínimo de FPS de 6, preconizado pela legislação brasileira para um produto ser utilizado em cosméticos fotoprotetores. Estudos posteriores de purificação destes extratos para identificação e seleção dos ativos de interesse, incorporação em formulações e avaliação de seu efeito como adjuvante devem ser conduzidos. 


\section{REFERÊNCIAS}

BANOV, D. et al. Caracterização do extrato seco de Ginkgo biloba L. em formulação de uso tópico. Acta Form. Bonaerense 25(2) : 219-24.2006.

BARROSO, Natália dos Santos. Maturação de frutos e viabilidade de sementes de Physalis ixocarpa Brot. ex Hormen. 2015. 39 f. Dissertação (Mestrado Acadêmico em Recursos Genéticos Vegetais) - Universidade Estadual de Feira de Santana, Feira de Santana, 2015.

BRASIL. Resolução - RDC N 30 de $1^{\circ}$ de junho de 2012. Aprova o Regulamento Técnico Mercosul sobre Protetores Solares em Cosméticos e dá outras providências. Diário Oficial [da] República Federativa do Brasil, Brasília, DF, 4 jun. 2012.

BOBIN, M. F.; RAYMOND, M.; MARTINI, M. C. UVA/UVB absorption properties of natural products. Cosmetics and toiletries, v. 109, n. 11, p. 63-70, 1994.

CEDEÑO, M.M.; MONTENEGRO, D.M. Plan exportador, logístico y de comercilizacion de uchuva al mercado de estados unidos para frutexpo S.C.I. Ltda. 2004. 134p. Monografia de conclusão de curso - Pontificia Universidad Javeriana, Bogotá, 2004.

DUTRA, E. A. et al. Determination of sun protection factor (SPF) of sunscreens by ultraviolet spectrophotometry. Revista Brasileira de Ciências Farmacêuticas, v. 40, n. 3, p. 381-385, 2004.

HERNANDEZ, J. F. S.; YANEZ, S. B. Aprovechamiento tradicional de las especies de Physalis en México. Revista de Geografía Agrícola, v. 43, p. 81-86, 2009.

MANSUR, J.S. et al. Determinação do fator de proteção solar por spectrofotometria. An Bras Dermatol, vol. 61, 121-124, 1986.

MARKHAM, K. R. et al. An increase in the luteolin: apigenin ratio in Marchantia polymorpha on UV-B enhancement. Phytochemistry, v. 48, n. 5, p. 791-794, 1998.

MARTÍNEZ-ROCHA, A. et al. Antioxidant and Antimutagenic Activities of Mexican Oregano (Lippia graveolens Kunth). Plant foods for human nutrition. 2008.

PERES, M. T. L. P et al. Estudos químicos e biológicos de Microgramma vacciniifolia (Lansd. \& Fisch.) Copel (Polypodiaceae). Química Nova, v. 32, n.4, p. 897-901. 2009.

RUFATO, L. et al. Aspectos técnicos da cultura da Physalis. Lages: CAV/UDESC, p. 457-463, 2008.

SOUSA, C. M. M. et al. Fenóis totais e atividade antioxidante de cinco plantas medicinais. Química Nova, v. 30, n.2. p. 351-355, 2007.

SOUZA, V.C.; LORENZI, H. Botânica Sistemática. Nova Odessa: Instituto Plantarum de Estudos da Flora Ltda, 2005.

STEHMANN, J.R. et al. Solanaceae. Lista de Espécies da Flora do Brasil. Jardim Botânico do Rio de Janeiro. Disponível em: <http://floradobrasil.jbrj.gov.br/jabot/floradobrasil/FB14696>. Acesso em: 9 Ago. 2017 TOMASSINI, Therezinha C. B. et al. Genus Physalis - a revision of withasteroids. Química Nova, v. 23, n. 1, p. 47-57, 2000.

VIOLANTE, I. M. et al. Avaliação in vitro da atividade fotoprotetora de extratos vegetais do cerrado de Mato Grosso. Rev Bras Farmacogn, v. 19, n. 2A, p. 452-57, 2009. 